\title{
PROCESSO DE FORMAÇÃO DAS ESTRATÉGIAS DE INTERNACIONALIZAÇÃO: ESTUDO DE CASO DA FINOBRASA
}

\author{
G. G. TASCA* e L. F. L. G. COSTA \\ Instituto Federal de Educação, Ciência e Tecnologia do Rio Grande do Norte \\ gabrielaguirao@hotmail.com*
}

Artigo submetido em novembro/2014 e aceito em novembro/2015

DOI: $10.15628 /$ holos.2015.2528

\section{RESUMO}

O presente artigo circunscreve a respeito da Finobrasa Agroindustrial S/A, uma empresa do Grupo Vicunha. Considerada, atualmente, a segunda maior exportadora de frutas do Rio Grande do Norte, a Finobrasa produz mais de 2 milhões de caixas de manga por ano. O objetivo principal é compreender o processo de formação e desenvolvimento das estratégias de internacionalização da empresa. Para tanto, foi realizado um estudo de caso, amparado pelos preceitos teóricos no tocante a formação de estratégia, sob a metodologia de caráter exploratório-descritivo, de natureza qualitativa (VERGARA, 2009; YIN, 2005). Para a coleta de dados, foi utilizado um questionário semiestruturado e entrevista respondida por um representante da empresa. Evidenciou-se a convergência entre a teoria disposta sobre as dimensões da estratégia - quais sejam: processo, conteúdo e contexto (DEWIT; MEYER, 2004; PETTIGREW, 1987) - com diversos aspectos práticos, desenvolvidos no cenário real.

PALAVRAS-CHAVE: formação da estratégia, dimensões da estratégia, internacionalização.

\section{PROCESS OF INTERNATIONAL STRATEGY FORMATION: FINOBRASA CASE}

\section{ABSTRACT}

The present work circumscribes regarding Finobrasa Agroindustrial S/A, a company from Vicunhas's Group. It is currently considered the second biggest fruit export in Rio Grande do Norte and produces more than 2 million boxes of mangos per year. The main objective is to analyze the process of forming and developing internationalization strategies at Finobrasa. For that, was made a case study, supported by theoretical precepts concerning to the strategy forming, under the descriptive-exploratory methodology, of qualitative
\end{abstract}

nature (VERGARA, 2009; YIN, 2005). It was consulted: books, scientific articles, monographs and websites. To collect data, it was used a semistructured survey and interview gave by a company's representative. It was evident the convergence between theory, arranged on the dimensions of the strategy - which are: process, content and context (DEWIT; MEYER, 2004; PETTIGREW, 1987 ) - to various practical aspects, developed in the real scenario.

KEYWORDS: strategy formation, strategy dimensions, internationalization 


\section{INTRODUÇÃO}

Historicamente a realidade brasileira apresenta uma economia voltada para o modelo de substituição de importações para atender à demanda interna (JÚNIOR, 1999). Contudo, a aceleração da globalização e da abertura comercial, ambas acentuadas no final dos anos 80, e início dos anos 90, resultou no modelo presente de desenvolvimento socioeconômico. O atual cenário um ambiente em constante evolução - demanda estratégias, preparação e adaptação contínua por parte das empresas brasileiras, para obtenção de êxito na competição econômica internacional.

No Rio Grane do Norte, entre os principais produtos da pauta exportadora, com relação a fruticultura, estão: melão, banana, mamão e manga (FIERN, 2012). Segundo Cavalcanti (1997), tais produtos sobressaem pela potencialidade produtiva da região e pelo incremento do seu consumo nos mercados internacionais. A boa qualidade do produto, dentro dos padrões requeridos, é estratégia fundamental de marketing para o sucesso do agronegócio. $O$ consumidor deseja frutas frescas, suculentas, de cor, forma e tamanho atrativos, sem a presença de resíduos químicos. Unidos, esses fatores agregam valor ao fruto e o torna não somente um alimento, mas um desejo em busca de satisfação e sabor.

A partir da década de 1960, os estudos sobre a internacionalização das empresas começaram a se consolidar, pois já se registrava a necessidade de comercialização e movimentação de capital entre os países. Atualmente, segundo Almeida (2007), a internacionalização se configura como algo inevitável.

No tocante ao processo de formação da estratégia, Pettigrew (1987) aponta o estudo acerca das dimensões: processo, conteúdo e contexto. Corroboram neste pensamento, autores como DeWit e Meyer (2004), afirmando que a estratégia diz respeito a como as empresas competem e buscam resultados superiores em seus negócios. Vale salientar também a existência dos paradoxos na formação da estratégia, quais sejam: pensamento lógico versus criativo, a formação de estratégia deliberada versus emergente e a mudança evolucionária versus revolucionária. Esses aspectos são geradores de grande divergência de opinião entre pensadores (CHAKRAVARTHY; LORANGE, 1991; MINTZBERG; WESTLEY, 2001),

Para esta análise, um estudo de caso caracterizado como exploratório-descritivo, de natureza qualitativa (VERGARA, 2007; YIN, 2005), foi feito um levantamento bibliográfico onde foram analisados volumes da literatura acadêmica, produzidos por autoridades no assunto. Outras fontes informativas, como artigos científicos, monografias (inclusive as dispostas no observatório de Comércio Exterior do IFRN) e websites, também colaboraram para o embasamento teórico. Já a coleta de dados foi direcionada, principalmente, por um questionário semiestruturado e entrevista respondida por um representante da empresa.

No foco deste trabalho está a Finobrasa Agroindustrial S/A, uma empresa do Grupo Vicunha, responsável pelo envio de mais de 2 milhões de caixas de mangas (anualmente) para mercados como: Estados Unidos, Holanda, Bélgica, Reino Unido e Espanha. No ranking norte rio grandense, em volume de exportações, a Finobrasa ocupa o 2 o lugar (MDIC, 2012), tendo galgado 5 posições nos últimos 5 anos. Diante o exposto, objetivou-se identificar e compreender como a Finobrasa desenvolve o processo de formação das estratégias de internacionalização. Procurouse, também, observar o nível de influência do conteúdo e contexto para o processo decisório das 
estratégias. Por fim, buscou-se verificar a congruência teórica em relação a formulação das estratégias com as práticas organizacionais aplicadas.

\section{REFERENCIAL TEÓRICO}

De acordo com Andrews (1987), estratégia organizacional é o padrão de decisões que revela os objetivos, propósitos e metas de determinada empresa; indica as políticas e planos traçados para obter resultados; define a gama de negócios almejados e a natureza econômica.

DeWit e Meyer (2004), afirmam que a estratégia diz respeito a como as empresas competem e buscam resultados superiores em seus negócios.

Não há um conceito único, ou definição universal aceita, contudo pode-se inferir que para alcançar o sucesso empresarial faz-se necessário, primeiramente, traçar um plano estratégico adequado e específico.

Definir estratégias requer estudo aprofundado da relação da organização (como um todo) com o seu meio envolvente, numa perspectiva completa. Para tanto, é necessário conhecer as dimensões da estratégia e suas minúcias. A seguir, serão apresentados preceitos teóricos, e possíveis contrapontos, no tocante aos elementos que compõe a estratégia, desde a sua formação.

\subsection{DIMENSÕES DA ESTRATÉGIA}

Segundo Pettigrew (1987) assim como uma caixa possui altura, largura e comprimento, a estratégia também possui dimensões fundamentais que podem ser identificadas e analisadas separadamente, no entanto, permanecem sendo parte intrínseca do todo.

As três dimensões da estratégia, segundo Pettigrew (1987) são: processo, conteúdo e contexto. Tais dimensões podem ser reconhecidas em praticamente todas as situações-problema reais, sendo: processo - a maneira pela qual a estratégia deve ser desenvolvida; conteúdo - o resultado obtido pela implementação da estratégia; e contexto - as circunstâncias sob as quais as atividades ocorrem.

Autores como Mintzberg e Westley (2001) criticam a versão tradicional e ressaltam que o processo de estratégia não se dá de forma linear e simples.

DeWit e Meyer (2004), ressaltam que é importante considerar a complexidade deste eixo tridimensional das dimensões estratégicas, e que o mesmo interage entre si, sendo preciso avaliar o nível de influência de cada dimensão, ponderando este impacto, de acordo com o objetivo organizacional.

\subsubsection{Dimensão de Processo}

Explorando primeiramente o processo da estratégia, tem-se a subdivisão deste em outras três dimensões: pensamento, formação e mudança. Nestas dimensões são analisadas questões como: quem está envolvido, onde ocorre o problema, como este será solucionado e quando as atividades estratégicas deverão ser implementadas. 
Cada subdivisão apresenta um paradoxo dúbio (DEWIT; MEYER, 2004), ou seja, dois perfis estratégicos que, ao decorrer do presente trabalho, serão vistos como opostos, porém, complementares.

\subsubsection{Pensamento Estratégico}

No pensamento estratégico há o paradoxo do pensamento lógico versus o pensamento criativo, sendo, o primeiro baseado na racionalidade e o conseguinte, na intuição.

Autores se contrapõem, uns defendendo a prevalescência da razão (CHAKRAVARTHY; LORANGE, 1991), outros a intuição (DEWIT; MEYER, 2004).

Independente da nuance de preferência, entender como funciona a mente de um estrategista possibilita a compreensão da estratégia utilizada. Para tanto, deve-se perceber o funcionamento do cérebro humano, cujo utiliza-se de três elementos para estruturar o raciocínio: a atividade cognitiva, a habilidade cognitiva e o mapa cognitivo.

As atividades gerais cognitivas são: identificar, diagnosticar, considerar e realizar. Ou seja, identificar a existência de um problema é o passo inicial para a resolução do mesmo. Logo, consideram-se as possíveis causas e em seguida aprecia-se as soluções plausíveis. Por fim, implementa-se a decisão, analisando os resultados.

\subsubsection{Paradoxo do Pensamento Estratégico: Lógico x Criativo}

Conforme enunciado anteriormente, o pensamento estratégico apresenta a tensão do pensamento lógico versus o criativo.

Apesar de autores como Isenberg (1984) inclinar à idealização da estratégia através da análise crítica, há grande aceitação pela utilização de ambos pensamentos, racional e empírico.

Na demanda vertical (DEBONO,1970), voltada ao pensamento lógico, as conclusões são baseadas no formato cascata, cada argumentação tem como alicerce os princípios válidos da análise anterior. Assim, a proposição final segue uma sucessão argumentativa, desembocando um desfecho lógico.

O pensamento criativo por sua vez, de demanda lateral, é guiado pela imaginação; abandona as regras e não segue razões sequenciais; os argumentos são soltos e as conclusões nem sempre fazem sentido.

Apesar de opostos, os pensamentos lógico e criativo, podem ser complementares. É um desafio assumi-los. Estrategistas carecem estar preparados para lidar com os conflitos emergentes do choque de estilo, mas ambos pensamentos, racional e emocional, são exigidos para a formulação de uma estratégia completa.

\subsubsection{Formação da Estratégia}

Conforme uma das definições já apresentadas: estratégia define o curso de ação a ser seguido pela organização para que esta atinja seu propósito. Contudo, Quinn (1978) afirma que o planejamento é somente um bloco na construção contínua dos eventos que realmente determinam a estratégia. 
Formação da estratégia é a colocação do planejamento em prática, perpassando as possíveis mudanças, e culminando na implementação (MINTZBERG; WESTLEY, 2001).

Retomando as atividades gerais cognitivas (identificar, diagnosticar, considerar e realizar), para ao desenvolvimento da formação estratégica, cada elemento subdivide-se em dois, gerando então oito ramificações, quais sejam: Missão e Reunião; Avaliação externa e interna; Geração e seleção de opções; Geração e seleção de opções; Tomada de ação e controle de desempenho.

\subsubsection{Paradoxo da Formação da Estratégia: Deliberada x Emergente}

Estratégias nada mais são que ações destinadas à resultados futuros, mas o amanhã é incerto e duvidoso. A principal tensão da formação da estratégia é ter que prever um futuro imprevisível, configurando a dualidade de querer desenhar o porvindouro, porém, adaptando-se aos desdobramentos realidade.

Pensar antes de agir configura a estratégia deliberada, onde os planos são feitos antes das ações. Não necessariamente precisam ser escritos, mas ao menos traçados, garantindo vantagens como: direção - a empresa desenha o rumo a ser seguido; cometimento - a equipe se engaja em trabalhar por um objetivo comum; coordenação: há sintonia nas tarefas realizadas; otimização: o investimento de recursos é consciente; programação: calendários podem ser mais facilmente cumpridos. (CHAKRAVARTHY; LORANGE, 1991),

Quando não há planos, ou quando o plano não é seguido, ainda há estratégia, sendo esta emergente, possível geradora de vantagens como: oportunismo - possibilita o aproveitamento de oportunidades não previstas; flexibilidade - planos irreversíveis não condizem com a instabilidade da realidade; aprendizado - a experiência só vem através de tentativas; empreendedorismo modificar o curso das ações incentiva a autonomia (MINTZBERG, 2001).

Observa-se que ambas as formações atraem benefícios e resultados, contudo, para empresas de grande porte, que envolvem-se em operações de risco, a estratégia deliberada aparenta ser a mais coerente, uma vez que, nem todos os negócios permitem inexatidões.

\subsubsection{Mudança Estratégica}

Em um mundo globalizado, em constante mudança e inovações a questão não é "se" as empresas devem mudar, mas quando e onde. Para manter-se efetiva e eficaz, empresas devem aprimorar os procedimentos já existentes, moldando novas atividades e reatribuindo tarefas. Adaptação é a palavra chave para sobreviver no mercado, seja no âmbito dos eventos externos, seja nas movimentações internas.

Mudanças operacionais são necessárias para conservar os sistemas, mudanças estratégias são direcionadas para renová-los. O desafio é identificar o momento certo para cada mudança e a velocidade cuja essa deve ser aplicada (DEWIT; MEYER, 2004).

Segundo Johnson (1988), as organizações apresentam dois sistemas principais, quais sejam: sistema de negócios e organizacional. Ambos são complexos e compostos por diferentes elementos.

O sistema de negócios é basicamente o modo como a empresa atinge seu maior objetivo. No caso das empresas não filantrópicas, a meta é obter lucro através de componentes como: recursos, produtos, serviços e valor agregado. 
Já o sistema organizacional refere-se ao modo como os componentes de negócios são alocados e interligam-se entre si a fim de atingir um objetivo maior. Toda e qualquer empresa deve estruturar e dividir suas responsabilidades, instituindo funções e afazeres.

\subsubsection{O Paradoxo da Mudança Estratégica: Evolucionária x Revolucionária}

É aceito entre a maioria dos estrategistas que uma empresa necessita balancear os processos de mudança, evolucionário e revolucionário, respectivamente relacionados às mudanças operacionais e estratégicas. Apesar de opostos e potencialmente contraditórios, apresentam características conflitantes, porém benéficas.

Evolução é o modo pelo qual uma corrente constante sofre alterações, modificando rotinas gradualmente. Ou seja, na abordagem evolucionária as mudanças acontecem, moderadamente, ao longo do tempo. O resultado acumulado é significativo (IMAI, 1986). A demanda da mudança evolucionária é como o aprendizado, um processo longo que requer tempo, contudo, provém experiência e crescimento.

A demanda da mudança revolucionária ocorre quando alterações de menor porte não satisfazem as necessidades organizacionais. Para implementá-la é preciso quebrar paradigmas e combater resistências psicológicas (medo do novo), resistências culturais (velhos costumes) e resistências políticas (enfrentar a oposição).

Por mais tênue que seja a mudança e mais sutilmente esta seja implementada, ainda assim, haverá necessidade de adaptação, reflexão e internalização. Do mesmo modo, variações bruscas, mesmo que necessárias, trarão efeitos significativos.

Assim como visto nas dimensões citadas anteriormente (pensamento e formação), o paradoxo da mudança estratégica revela que é preciso balancear as decisões entre as opções opostas. A tendência unilateral restringe e desfavorece a estratégia.

\subsubsection{Dimensão de Conteúdo}

Na visão de Pettigrew (1987), a dimensão do conteúdo apresenta o produto obtido pela implementação das estratégias e o modo como estas foram formuladas. Refere-se ao que mudou na organização, pautando as percepções gerenciais em relação a forma como estas mudanças influenciam nas operações da empresa.

Cada estratégia é essencialmente única e adere à princípios diferentes em função das questões de maior relevância. As estratégias de conteúdo identificam quais os melhores caminhos em detrimento de outras escolhas.

O processo decisório é pautado de acordo com a influência dos níveis de estratégia, quais sejam: Funcional; Negócios; Corporativo; de Redes.

Os níveis das estratégias de conteúdo não são rigorosamente dispostos, mas fortemente correlacionados e parcialmente sobrepostos. Assim, a escolha de quaisquer estratégias interfere na possível aplicação de outra.

Johanson e Vahlne (1977) denotam que as empresas brasileiras, no seu estágio inicial, tendem superestimar o processo da estratégia, em especial no tocante a formação deliberada, muito timidamente influenciada pela dimensão conteúdo. 


\subsubsection{Dimensão de Contexto}

Dadas as outras duas dimensões da metodologia de Pettigrew (1987), processo e conteúdo, resta então a análise do contexto.

O contexto é tido como as circunstâncias sob as quais o processo e conteúdo ocorrem. Não é definido se este pode ser moldado ou se ocorre por si só, mas de qualquer maneira é imprescindível adaptar-se.

A determinação das estratégias de contexto variam de acordo com a influência das seguintes superfícies: organizacional, industrial e internacional (DEWIT; MEYER, 2004).

No contexto organizacional indaga-se a influência das organizações na determinação do processo e conteúdo, e o poder dos estrategistas em controlar o curso das ações.

Já no contexto industrial é questionado o quanto as circunstâncias da indústria (na qual a empresa está inserida) definem as regras sob as quais a organização deve agir, e quando esta tem liberdade para escolher sua própria estratégia, inclusive modificando as condições da própria indústria.

Por fim, no contexto internacional abre-se a discussão para a necessidade de adaptação à adversidade e/ou a liberdade de escolha da estratégia, havendo, ou não, notoriedade de ajustes.

\section{APRESENTAÇÃO DOS DADOS}

\subsection{ASPECTOS GERAIS DA EMPRESA}

A Finobrasa Agroindustrial é uma empresa do grupo Vicunha. Surgiu como uma alternativa de negócio da Fiação Nordeste do Brasil Finobrasa S/A cuja perdeu todo seu cultivo de algodão em virtude da praga do bicudo, que assolou a industrial têxtil nacional nos anos 80 .

Sediada no polo fruticultor do vale do Açu, oeste potiguar, a empresa cultiva mais de 1000 hectares de mangas, destinadas prioritariamente ao mercado internacional, tais como: Estados Unidos, Reino Unido, Alemanha, Bélgica e Espanha. Somente no segundo semestre do ano corrente, impulsionados pela baixa precipitação das chuvas, serão mais de 470 contêineres enviados ao exterior, ultrapassando 2 milhões de caixas de manga.

Atualmente a Finobrasa é a segunda maior exportadora de frutas do Rio Grande do Norte (MDIC, 2012), tendo galgado 5 posições nos últimos 5 anos.

Considerada uma empresa de médio porte, durante o período entressafra (agosto a novembro), chega a apresentar um quadro corporativo com mais de 1000 colaboradores, sendo 350 fixos, e os demais absorvidos através de contratos temporários.

Devido ao solo fértil e favorável clima da região, a produção ocorre durante praticamente o ano todo, concentrando-se nos períodos de agosto a abril de cada ano. Assim, é possível atender os mercados americano e europeu.

Mais de $70 \%$ da produção é de manga do tipo Tommy Atkins, conhecida popularmente como manga rosa. Contudo, outros tipos como Keitt, Kent e Palmer, também são comercializados. 


\section{ANÁLISE DOS RESULTADOS}

Assim como as dimensões da estratégia são unidades distinguíveis, mas parte intrínseca de um todo, o processo de formação e desenvolvimento das estratégias de internacionalização da Finobrasa, naturalmente, constituem um conjunto de elementos que podem ser identificados e desmembrados.

A presente análise de resultados define-se como exploratória, pois não constatou-se estudos prévios com enfoque específico nas estratégias de internacionalização da Finobrasa. Os dados foram coletados através de questionário semiestruturado e respondido em entrevista direta por colaborador atualmente registrado na empresa e responsável pelo processo de exportação. A extração dos resultados se deu por meio da observação das informações obtidas com o questionário e sua congruência, ou não, ao levantado nas pesquisas teóricas.

\subsection{RESULTADOS DA ANÁLISE DA DIMENSÃO DE PROCESSO}

\subsubsection{Pensamento Estratégico}

Com relação ao processo estratégico, o pensamento lógico claramente sobressai ao criativo e apesar do ponto de partida ser intuitivo (como a própria abertura da empresa, tendo em vista a crise no setor têxtil), as decisões só são concretizadas mediante análise racional.

A decisão do produto também foi pautada na razão, sendo a manga uma fruta de maior aceitação no mercado.

Observa-se, então, que a idealização da estratégia através da análise crítica, defendida por Isenberg (1984), prevalece.

Ainda assim, vale ressaltar que até mesmo a racionalidade contém intuição, pois a estratégia organizacional é inerente ao comportamento dos gestores, e em sendo o nível hierárquico da Finobrasa bem definido e verticalizado, a tomada de decisões baseia-se então nas estruturas de conhecimento de cada gestor, ou seja, em seus mapas cognitivos.

Ou seja, apesar da presença da demanda vertical voltada ao pensamento lógico, indicado por Debono (1970), o conhecimento adquirido no "esquema cognitivo" de Mccaskey (1982) influencia a tomada de decisões e, por consequência, o pensamento estratégico.

\subsubsection{Formação da Estratégia}

Consoante ao paradoxo apresentado na formação da estratégia, a Finobrasa pende expressivamente às ações deliberadas - perfil clássico do setor, afinal a agricultura não ocorre de uma hora para a outra, mas depende de um grande e condizente planejamento para dar certo. Subordinado às condições climáticas, o plantio deve seguir um calendário rígido, a fim de otimizar os recursos, garantindo uma safra rica em qualidade e quantidade.

As vantagens por apresentar o perfil defendido por Chakravarthy e Lorange (1991) são nítidas pois a empresa segue um rumo determinado (metas e calendários), ciente do caminho a percorrer (procedimentos claros e funções determinadas) e também dos possíveis obstáculos a ultrapassar (como chuvas e pragas), alinhando as tarefas e principalmente a logística. 
Contudo, ações emergentes, como as indicadas por Mintzberg (2001), apesar de refletirem a tendência desse novo mercado - dinamizado e imediatista - não corroboram com as atividades do cultivo de manga, cujo está aberto à melhorias, mas indisponível à riscos.

Empresas do porte da Finobrasa (onde mais de 1000 colaboradores fomentam o desenvolvimento da região) não podem flexibilizar-se ao ponto de aprender com erros. As estratégias devem ser assertivas e geradoras de resultados. Neste cenário, a autonomia e empreendedorismo são incumbências da diretoria.

\subsubsection{Mudança Estratégica}

Observando o futuro e ciente da necessidade contínua de aprimoramento e adaptação, a empresa não aponta receios à mudanças, entretanto, as reformulações ocorrem de forma gradativa. Ficando claro então o apresentado por Dewit e Meyer (2004), onde, as mudanças operacionais são necessárias para conservar os sistemas e as mudanças estratégicas são necessárias para renová-los.

Ao longo dos anos o foco foi sendo alterado e a empresa que foi criada para ser apenas o desmembramento de um grupo - como uma medida emergencial oportuna - consolidou-se no mercado como uma das maiores exportadoras no Rio Grande do Norte.

Incialmente as exportações ocorreram de forma pontual, aproveitando-se da taxa cambial da época e destinos seguros. Porém, em virtude da expansão e progresso do sistema de negócios, o foco passou a ser o desenvolvimento do produto manga em si, e conquista de novos mercados.

Atender as exigências da rigorosa demanda internacional incitou a Finobrasa a efetuar investimentos em áreas como a tecnologia, provocando então, mudanças no sistema organizacional. A anatomia, fisiologia e psicologia da empresa foram progressivamente adaptadas aos novos padrões de produção, com maquinários novos e complexos.

Adaptação também aos fatores culturais e linguísticos, confrontados tanto nos mercados já atuantes, quanto nos vindouros. Pesquisas e sondagem de ambiente são ações chave que minimizam entraves no relacionamento com clientes.

Tem-se então a presença da separação do sistema organizacional de acordo com Bartlett e Ghoshal (1995): estrutura, processos e cultura. Bem como, ênfase às questões comportamentais e culturais intrínsecas às mudanças, conforme indicado por Lawerence e Lorsch (1972).

\subsection{RESULTADOS DA ANÁLISE DA DIMENSÃO DE CONTEÚDO}

O conteúdo, que como visto, na visão de Pettigrew (1987) é o produto obtido pela implementação das estratégias, reflete-se no caso Finobrasa justamente no crescimento e evolução da empresa, que, a cada ano, ultrapassa seu próprio limite de exportações.

A relevância e influência do nível funcional - aquele relativo aos aspectos operacionais (tarefas) - concerne principalmente as atividades efetuadas no Packing House (galpão de embalagem), onde é feita a ovação de contêineres, pois conforme comentado anteriormente, o manuseio da fruta é crucial e diretamente ligado a qualidade e potencialidade de comercialização. No mercado exterior, as características externas (aparência) da fruta são fator determinante no processo decisório da compra. 
Orientado pelo mercado e pelos recursos, o nível de negócios está presente na política de diversificação, pois além do cultivo da manga rosa (Tommy Atkins), a mais exportada no mundo, a Finobrasa também desenvolve outros tipos como Keit, Kent e Palmer. Pode-se inferir que neste setor da fruticultura, a empresa apresenta a situação que deveria apresentar e aproveita um momento de estabilidade.

Apesar de pertencer ao grupo Vicunha, a Finobrasa detém sua autonomia, assim, no tocante ao nível corporativo, se satisfaz na condição de Sociedade Autônoma, não tendo planos, a curto prazo, de abertura de capital. Este cenário remete ao nível de relacionamento, que atualmente não dispõe de alianças estratégicas com outras empresas, senão as importadoras do produto.

\subsection{RESULTADOS DA ANÁLISE DA DIMENSÃO DE CONTEXTO}

As circunstâncias sob as quais o comércio internacional acontece, ou seja, o contexto no qual insere-se a atuação da Finobrasa é o fator de mais densa influência dentre as dimensões da estratégia.

No contexto organizacional tem-se a condição dos estrategistas em coordenar o fluxo e curso das ações. Observa-se então, escolhas como: a localização da empresa em virtude do solo fértil, cujo propicia uma produção prolongada; a utilização de portos vizinhos como estratégia de escoamento, visto a insuficiência do Porto de Natal; e o aproveitamento de incentivos á exportação como o regime especial de Drawback e financiamentos com bancos de primeira linha.

No âmbito do contexto consideremos "indústria" uma referência ao cenário do setor, que no caso é o primário (agricultor). Neste enredo podemos ressaltar as exigências fitossanitárias, que modificam o processo produtivo, tendo em vista a saúde e bem estar do consumidor. A Finobrasa dispõe de todas as certificações exigidas como presença de resíduos e fumigação de pallets controle de pragas porventura constantes na madeira.

Por fim, na discussão do contexto internacional tem-se os eventos intervenientes, teoricamente não controláveis, consoantes ao comportamento do mercado externo.

A própria decisão pela internacionalização foi guiada pelas variáveis contextuais, as quais indicaram as oportunidades das janelas de mercado, tendo em vista as condições econômicas vividas pela empresa.

Atualmente, as oscilações dos mercados, principalmente Estados Unidos e Europa, ditam as regras de atuação. Contudo, novos destinos já foram colocados em pauta, como o Oriente Médio, mas essa prospecção ainda será sistematizada.

\section{CONSIDERAÇÕES FINAIS}

O processo de formação e desenvolvimento das estratégias de internacionalização definitivamente não trata de esquemas pré-elaborados e aplicação uniforme. Para cada empresa, e para cada parte dessa empresa, as estratégias devem ser especificamentes instauradas, a fim de garantir o alcance dos objetivos.

No caso da Finobrasa, a formação e desenvolvimento da estratégia de internacionalização, até o momento, tem se apresentado adequados e extremamente eficazes. Essa conclusão pode 
ser auferida tendo por base o crescimento contínuo e expressivo ( 5 posições em 5 anos) da empresa junto a pauta de exportações do estado (MDIC, 2012). A empresa está ciente de seus alvos e direciona seus esforços com foco.

No tocante aos paradoxos do processo da estratégia, observou-se a propensão sempre por um dos comportamentos. A congruência se deu da seguinte forma: pensamento lógico, formação deliberada e mudança evolucionária. Ou seja, de maneira geral, a Finobrasa apresenta estratégias formadas pelo raciocínio lógico, comandadas preponderantemente pelos seus dirigentes e as mudanças são implementadas em velocidade moderada.

O conteúdo é perceptível através dos níveis de desempenho obtidos pela Finobrasa e os resultados são, de fato, utilizados como parâmetro para a aplicação, modificação ou interrupção de estratégias.

No início de suas atividades a empresas sofria alta influência do ambiente externo e baixa influência do ambiente interno, contudo, ao longo dos anos, passou a indicar alta influência de ambos os ambientes. O mercado doméstico apesar de não ser um grande destino, fomenta a exportação, cuja está suscetível às variações do contexto global.

A análise do processo de formação das estratégias de internacionalização da Finobrasa, demonstrou sensatez, profissionalismo e principalmente alto nível de planejamento por parte da empresa, em todas as etapas da atividade - desde o cultivo, perpassando o transporte, até a comercialização no exterior. O cultivo é devidamente planejado seguindo o calendário agrícola; o transporte é organizado de forma a não prejudicar o produto por demora, falta de refrigeração ou má acondicionamento; e a comercialização no exterior é condicionadas à cliente idôneos e formas de pagamento que asseguram o exportador.

O estudo voltado ao nível de influência do conteúdo e contexto para o processo decisório das estratégias, apresentou, além da verticalização na tomada de decisões, a interconectividade entre os níveis corporativos e as superfícies organizacionais.

A principal estratégia identificada foi o aproveitamento das janelas de mercado, em virtude da observação das oscilações transcorridas no comércio internacional.

Por meio das constatações já apresentadas na Análise dos Resultados, houve convergência teórica em relação a formulação das estratégias com as práticas organizacionais aplicadas, com ênfase nos paradoxos.

Em síntese, a compressão do processo de formação das estratégias de internacionalização da Finobrasa possibilita esclarecer os motivos pelos quais a empresa tem alcançado grande sucesso no ramo.

\section{REFERÊNCIAS}

1. ALMEIDA, André. Internacionalização de empresas brasileiras, perspectivas e riscos. Rio de Janeiro: Elsevier, 2007

2. ANDREWS, K. R. The concept of corporate strategy. 1987. In: Strategy: Process, Content and Context. Italy: Thomson, 2004.

3. BARDIN, L. Análise de conteúdo. Lisboa: Edições 70, 1977. 
4. BARLETT. A; GHOSHAL. S. Transnational Management. 1995. In: Strategy: Process, Content and Context. Italy: Thomson, 2004.

5. BRASIL, Federação das Indústrias do Estado do Rio Grande do Norte. Disponível em: <http://www.fiern.org.br/images/PDF/CIN/Dados_Estatisticos/ exportacoes_do_rn_junho_e_acumulado_2012.pdf>. Acesso em: 16 jun 2012.

6. BRASIL. Ministério do Desenvolvimento da Indústria e Comércio. Disponível em: <http://www.mdic.org.com.br>. Acesso em: 02 jul 2012.

7. BRECHT, J. K. Manual de práticas para melhor manejo pós-colheita da manga. São Paulo: National Mango Board, 2011.

8. CARVALHO, Débora. Entraves a competitividade. Revista Desafios do Desenvolvimento, Brasília, v1. n1, abr./nov. 2009.

9. CAVALCANTI, Josefa S. B. Frutas para o mercado global. São Paulo: Estudos avançados. Vol 11, n.29. Abr. 1997.

10. COSTA, Lúcia; AÑEZ, Miguel. Processo de internacionalização da fruticultura do RN: o caso finobrasa. Revista Eletrônica do Mestrado Profissional em Administração da Universidade Potiguar, Natal, Ano III, n. 2 - abr./set. 2011.

11. CHAKRAVARTHY B. S.; LORANGE, P. Managing the strategy process: a framework for a multibussiness firm. 1991. In: Strategy: Process, Content and Context. Italy: Thomson, 2004.

12. DAY, D.V; LORD, R. G. 1992. Expertise and problem categorization. In: Strategy: Process, Content and Context. Italy: Thomson, 2004.

13. DEBONO, E. Lateral thinking. 1970. In: Strategy: Process, Content and Context. Italy: Thomson, 2004.

14. DeWIT, B; MEYER, R. Strategy: Process, Content and Context. Italy: Thomson, 2004.

15. FINKELSTEIN, S; HAMBRICK, D. C. Strategic Leadership. 1996. In: Strategy: Process, Content and Context. Italy: Thomson, 2004.

16. FINOBRASA AGROINDUSTRIAL. Blog do Carlos Escócia. Disponível em: <http://www.carlosescossia.com/2010/10/finibrasa-agroindustrial.html>. Acesso em: 22 jun 2012.

17. GREINER, L. E. "Evolution and revolution as organization grow". Harvard Business Review. Vol:50. No. jul./ago, pp. 37-36. 1972.

18. ISENBERG, D. J. "How senior Managers Think". 1984. In: Strategy: Process, Content and Context. Italy: Thomson, 2004.

19. IMAI, M. The key to Japan's competitive success. 1986. In: Strategy: Process, Content and Context. Italy: Thomson, 2004.

20. JOHANSON, J; VAHLNE, J. The internationalization process of the firm. Journal of International Business Studies, p.23-32, maio/outubro 1977.

21. JOHNSON, G. "Rethinking Incrementalism". 1988. In: Strategy: Process, Content and Context. Italy: Thomson, 2004.

22. JÚNIOR, Farah. A empresa brasileira e os desafios da globalização: o papel da pesquisa científica na busca de novos modelos de gestão. Revista FAE, Curitiba, v. 2, n. 2, mai./ago. 
1999.

23. LYLES, M. A; SCHWENK, C. R. Top Management, strategy and organization knowledge structures. 1992. In: Strategy: Process, Content and Context. Italy: Thomson, 2004.

24. MCCASKEY, M. B. The Executive Challenge: Managing Change and Ambiguity. 1982. In: Strategy: Process, Content and Context. Italy: Thomson, 2004.

25. MINERVINI, Nicola. O Exportador: Ferramentas para atuar com sucesso no mercado internacional. 5.ed. São Paulo: Pearson Prentice Hall, 2008.

26. MINTZBERG, H.; WESTLEY, F. Decision-making: it's not what you think. Sloan Management Review, vol. 42, n. 3, out./dez. 2001.

27. MORAES, Roque. Análise de conteúdo. Revista Educação, Porto Alegre, v. 22, n. 37, p. 7-32, 1999.

28. PetTigreW, A. M. Context and action in the transformation of the firm. Journal of Management Studies, v. 24, 1987.

29. PORTER, Michael E. Estratégia Competitiva: Técnicas para análise de indústrias e da concorrência. 30. ed. Rio de Janeiro: Campus, 1980.

30. QUINN, J. B. Strategic change: logical incrementalism. Sloan Management Review, ago./nov. 1978.

31. SCHRAMM, W. Notes on case studies of instructional media projects. Working paper, The academy for educational development, Washington, DC, 1971.

32. VERGARA, Sylvia Constant. Projetos e relatórios de pesquisa em administração. 9 e.d. São Paulo: Atlas, 2007.

33. VALEXPORT. Disponível: <http://www.valexport.com.br>. Acesso em 8 jul. 2012).

34. YIN, Robert K. Estudo de Caso. USA: Sage Publications Inc., 2005. 